\title{
Comparison of Different Modulation Strategies Applied to PMSM Drives Under Inverter Fault Conditions
}

\author{
Jorge O. Estima and A.J. Marques Cardoso \\ University of Coimbra, FCTUC/IT, \\ Department of Electrical and Computer Engineering, \\ Pólo II - Pinhal de Marrocos, P - 3030-290, Coimbra, Portugal \\ Phone/Fax: +351 239796 232/247 \\ jestima@ieee, ajmcardoso@ieee.org
}

\begin{abstract}
This paper presents a comparative study of two distinct modulation strategies applied to a permanent magnet synchronous motor drive, under inverter faulty operating conditions. A rotor field oriented control is used and a performance evaluation is conducted by comparing a hysteresis current control with a space vector modulation technique. Three different operating conditions are considered: normal situation, a single power switch open-circuit fault and a single-phase open-circuit fault. In order to compare the drive performance under these conditions, global results are presented concerning the analysis of some key parameters such as motor efficiency, power factor, electromagnetic torque and currents rms and distortion values.
\end{abstract}

Keywords: Permanent magnet synchronous motor, hysteresis current control, space vector modulation, inverter open-circuit faults.

\section{Introduction}

Permanent magnet synchronous motors (PMSM) employed in AC drive systems are usually fed by six-switch three-phase voltage source inverters. Due to their complexity, it is known that these devices are very susceptible to the occurrence of failures, either in the power stage or in the control subsystem. These can be broadly classified as shortcircuit faults and open-circuit faults. Short-circuits represent the most serious class of faults. In case of a single power device short-circuit, the second switch in the same inverter leg has to be turned off immediately to avoid a dangerous shoot-through inverter failure. Open-circuit failures may occur when, for any reason, the semiconductor is disconnected, damaged or due to a problem in the gate control signal.

Some studies can be found in the literature concerning the analysis of PMSM drives under different faulty operating conditions. In [1], the effects on currents, voltages and torque of different drive failures such as switch-on failures, single-phase open-circuit, switch-off and DC supply failures, are investigated. The steady state and dynamic response of a PMSM drive to a single-phase open-circuit fault is investigated in [2], and in [3] symmetrical and asymmetrical short-circuit faults are considered.

Major potential faults that can occur in PMSM drives are discussed and simulated in [4]. Single-phase open-circuit and short-circuit faults, three-phase short-circuit faults and single switch-on failures are considered. 
Several performance analysis of a PMSM drive under a single power switch and single-phase open-circuit faults in the inverter are reported in [5]-[7]. Through the evaluation of some key parameters, it was concluded that a single-phase open-circuit fault has a greater negative impact on the PMSM performance than a single power switch open-circuit failure.

This paper intends to present a comparative analysis between two different PWM strategies applied to PMSMs control, namely, a rotor field oriented control with hysteresis current controllers and with space vector PWM (SV-PWM), under inverter faulty operating conditions. Three distinct operating conditions are considered normal behavior, a single power switch open-circuit fault and a single-phase opencircuit fault in the inverter. A typical three-phase diode bridge rectifier, a VSI and a PMSM are used, as shown in Fig. 1.

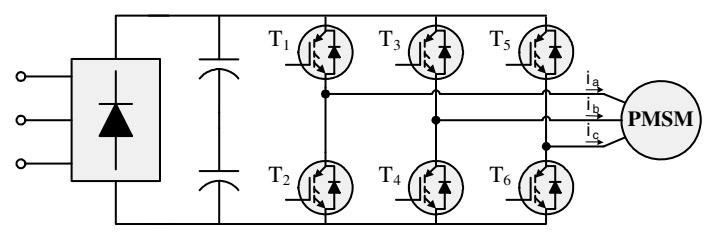

Fig. 1. Structure of the PMSM drive

The PMSM performance evaluation for both control strategies is based on the analysis of some key parameters such as motor efficiency, power factor, electromagnetic torque and currents rms and harmonic distortion values.

\section{Contribution to Technological Innovation for Sustainability}

Due to the arising concerns about global warming and energy resources constraints, there is nowadays an increasing demand for high-efficient energy conversion systems. Therefore, and considering also the large impact of electric motor drives energy consumption in the worldwide industry, the subject discussed in this work can contribute to the technological innovation for sustainability since, among other things, a comparison of efficiency levels is performed.

\section{PMSM Dynamic Model Equations}

Typical PMSM mathematical models found in the literature do not take iron losses into account. For this reason, in order to obtain a more accurate modeling, especially for the iron losses, a dedicated parameter has been considered aimed at accounting for the iron losses in the stator core, specifically the eddy current losses. These are modeled by a resistor $R_{c}$ which is inserted in parallel with the magnetizing branch, so that the power losses depend on the air-gap flux linkage [6]. Therefore, assuming that the saturation is neglected, the electromotive force is sinusoidal and a cageless rotor, the stator $d q$ equations in the rotor reference frame are: 


$$
\begin{gathered}
v_{d}=R_{s} i_{d}+L_{d} \frac{d i_{m d}}{d t}-\omega L_{q} i_{m q} \\
v_{q}=R_{s} i_{q}+L_{q} \frac{d i_{m q}}{d t}+\omega L_{d} i_{m d}+\omega \psi_{P M}
\end{gathered}
$$

where $v_{d}$ and $v_{q}$ are the $d q$ axes voltage components, $R_{s}$ the stator winding resistance, $i_{d}$ and $i_{q}$ the $d q$ axes supply currents, $L_{d}$ and $L_{q}$ the $d q$ axes inductances, $i_{m d}$ and $i_{m q}$ the $d q$ axes magnetizing currents, $\omega$ the fundamental frequency and $\psi_{P M}$ the flux linkage due to the rotor magnets.

The PMSM electromagnetic torque $T_{e}$ equation is given by:

$$
T_{e}=\frac{3}{2} p\left[\psi_{P M} i_{m q}+\left(L_{d}-L_{q}\right) i_{m d} i_{m q}\right]
$$

being $p$ the machine pole pairs number.

\section{Results}

The modeling and simulation of the drive was carried out using the Matlab/Simulink environment, in association with the Power System Blockset software toolbox. A rotor field oriented control strategy was implemented for a PMSM employing a hysteresis current control, in the $a b c$ reference frame, and a space vector PWM (SV-PWM). The value of the hysteresis band was defined to $0.3 \mathrm{~A}$ and the SV-PWM switching frequency was chosen to be $8 \mathrm{kHz}$. Three different operating conditions are considered: normal situation, an inverter single power switch open-circuit fault (IGBT T1) and a single-phase open-circuit failure (double fault in IGBTs T1 and T2).

The PMSM phase currents are analyzed by the calculation of their rms and distortion values using the Total Waveform Distortion (TWD) defined as:

$$
\mathrm{TWD}=\frac{\sqrt{X_{\mathrm{rms}}^{2}-X_{1}^{2}}}{X_{1}} \times 100 \%
$$

being $X_{\mathrm{rms}}$ the waveform rms value and $X_{1}$ its respective fundamental component.

In order to study the electromagnetic torque developed by the PMSM for the considered cases, a Total Waveform Oscillation (TWO) parameter is also introduced, which is given by:

$$
\mathrm{TWO}=\frac{\sqrt{T_{e_{\mathrm{rms}}}^{2}-T_{e_{\mathrm{dc}}}^{2}}}{\left|T_{e_{\mathrm{dc}}}\right|} \times 100 \%
$$

where $T_{e_{\mathrm{rms}}}$ and $T_{e_{\mathrm{dc}}}$ stand for the electromagnetic torque rms and average values, respectively.

Finally, for all the considered operating conditions, a constant load torque equivalent to $28 \%$ of the PMSM rated torque is assumed, together with a reference speed of 1200 revolutions per minute. 


\subsection{Normal Operating Conditions}

Fig. 2 presents the time-domain waveforms of the motor phase currents obtained for a hysteresis current control and for a space vector PWM technique under normal operating conditions. Fig. 3 presents their corresponding rms and distortion values.

As expected, under healthy operating conditions, the PMSM phase currents are practically sinusoidal, containing a well-defined fundamental component and low amplitude high-frequency noise. However, in spite of their rms values are the same for both modulation strategies (Fig. 3(a)), it can be seen that with a SV-PWM technique, it is possible to achieve lower distortion values (Fig. 3(b)).

Fig. 4(a) and Fig. 4(b) present the spectrograms of the electromagnetic torque and their corresponding time-domain waveforms for a hysteresis current control and for a SV-PWM, respectively. Under normal operating conditions, there are no appreciable differences between both cases, leading to a similar TWO value.

Regarding the PMSM power factor, the results in Fig. 5(a) show that with a hysteresis current control, the obtained power factor value is considerably lower than with a SV-PWM strategy. This is justified by the larger rms values of the supplying voltage generated by the hysteresis controllers, which lead to the increasing of the apparent power and the subsequent decrease of the machine power factor.

Fig. 5(b) presents the PMSM efficiency values for both the considered modulation strategies. Once more, the use of SV-PWM allows to achieve higher efficiency values since, as previously mentioned, with a hysteresis current control, larger voltage rms values are applied to the machine, contributing considerably to the increase of the PMSM iron losses.
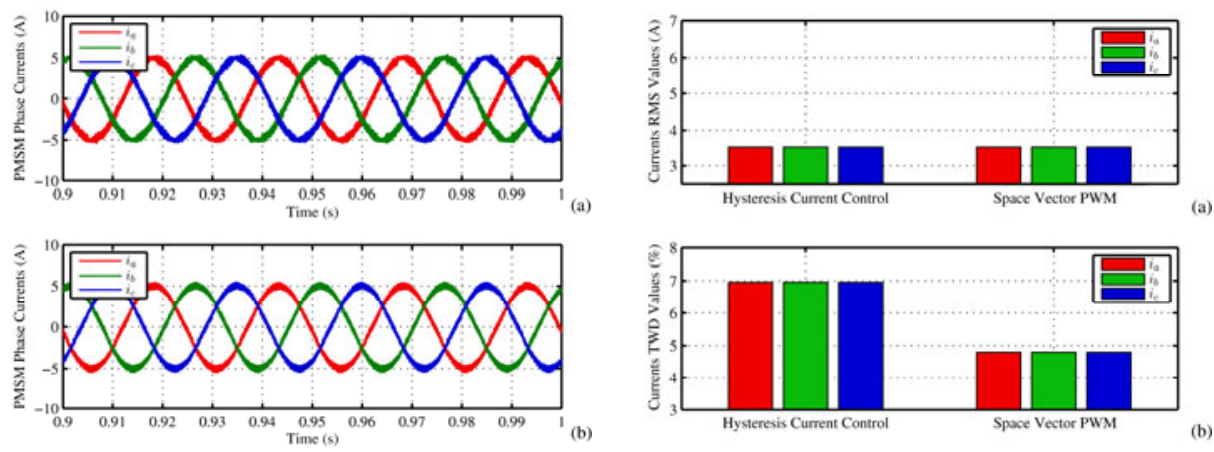

Fig. 2. Time-domain waveforms of the PMSM phase currents under normal operating conditions: (a) hysteresis current control;

Fig. 3. PMSM phase currents rms (a) and TWD values (b) under normal operating conditions 


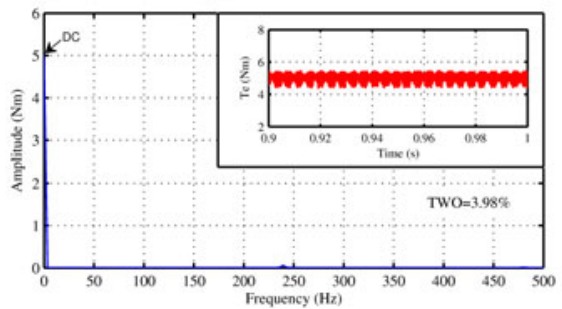

(a)

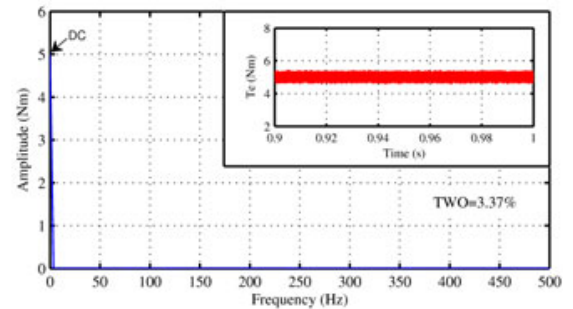

(b)

Fig. 4. Spectrograms of the PMSM electromagnetic torque and its corresponding time-domain waveforms under normal operating conditions: (a) hysteresis current control; (b) SV-PWM

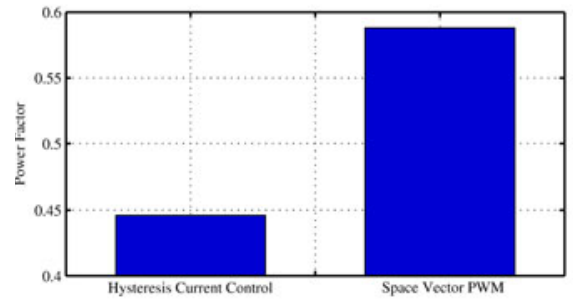

(a)

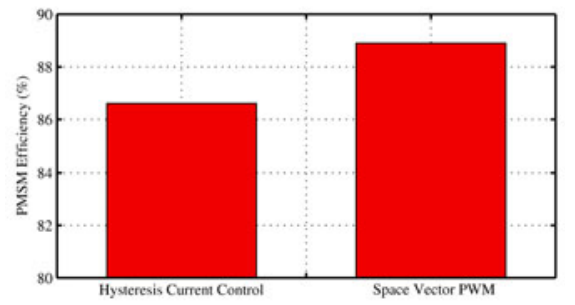

(b)

Fig. 5. PMSM power factor and efficiency results under normal operating conditions: (a) power factor values; (b) efficiency values

\subsection{Single Power Switch Open-Circuit Fault}

Fig. 6 presents the time-domain waveforms of the motor phase currents obtained for a hysteresis current control and for a space vector PWM technique with a single power switch open-circuit fault in transistor T1. Fig. 7 presents their corresponding rms and distortion values. It can be clearly seen that, under these conditions, the motor phase currents do not have a sinusoidal shape anymore. This unbalanced inverter topology also influences the currents rms values, where the affected phase (phase $a$ ) will have the lowest value, increasing the remaining values of the healthy inverter legs. Comparing with normal operating conditions, the TWD values increase significantly, particularly for the faulty phase. However, comparing both modulation strategies, the SV-PWM has a better behavior since it generates less harmonic distortion on the two healthy phases.

The results presented in Fig. 8 show that the PMSM electromagnetic torque is no longer constant, containing harmonics multiple of the fundamental currents frequency. The main pulsating component is less significant for the SV-PWM control, which contributes to a lower TWO value and a smoother torque.

Fig. 9 presents the results concerning the PMSM power factor and efficiency. Comparing with the healthy operating conditions, although all values are negatively affected by the fault, the SV-PWM technique has a better performance since it allows to achieve higher power factor and efficiency values. 

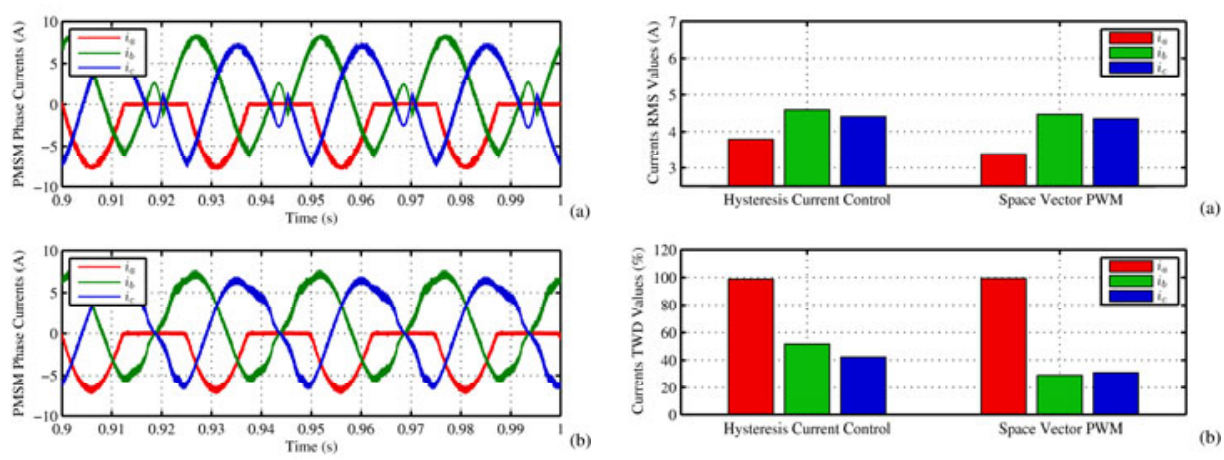

Fig. 6. Time-domain waveforms of the PMSM phase currents for an open-circuit fault in transistor T1: (a) hysteresis current

Fig. 7. PMSM phase currents rms (a) and TWD values (b) for an open-circuit fault in transistor $\mathrm{T} 1$

control; (b) SV-PWM

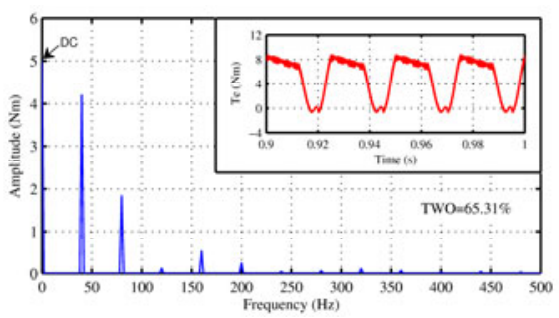

(a)

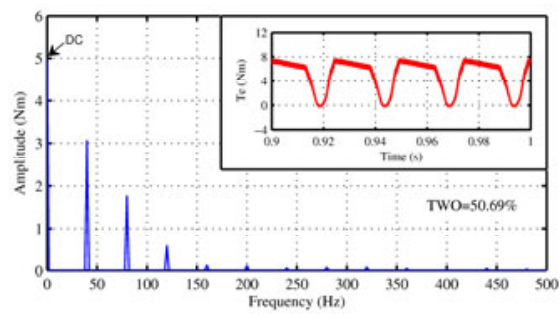

(b)

Fig. 8. Spectrograms of the PMSM electromagnetic torque and its corresponding timedomain waveforms for an open-circuit fault in transistor T1: (a) hysteresis current control; (b) SV-PWM

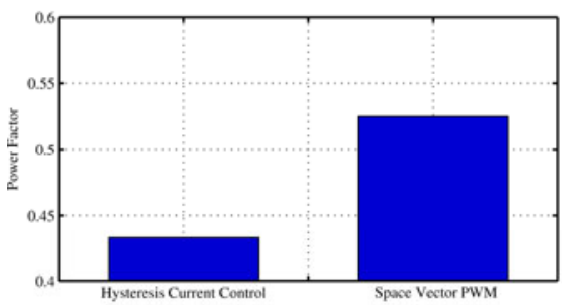

(a)

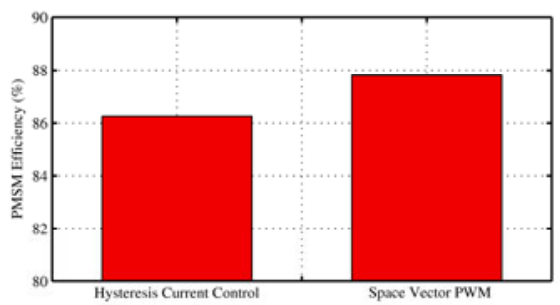

(b)

Fig. 9. PMSM power factor and efficiency results for an open-circuit fault in transistor T1: (a) power factor values; (b) efficiency values 


\subsection{Single Phase Open-Circuit Fault}

Fig. 10 and Fig. 11 present the time-domain waveforms of the motor phase currents and their corresponding rms and distortion values obtained for the two considered techniques with a single-phase open-circuit fault in phase $a$. As expected, under these conditions the current in phase $a$ is null. However, it is verified that the two remaining currents amplitude is larger for a hysteresis current control, which contributes to a greater thermal stress imposed on the stator windings insulation. Furthermore, the TWD results show that the SV-PWM has a better behavior since it generates much less harmonic distortion than the hysteresis current control.

The time-domain waveforms of the electromagnetic torque developed by the PMSM (Fig. 12) confirm its very pulsating nature. Comparing both modulation strategies, the SV-PWM leads to the creation of a less pulsating torque, which means that as far as the motor is concerned, the produced mechanical stresses are reduced, comparing with a hysteresis current control.

Regarding the power factor results presented in Fig. 13(a), despite the noticeable increase of the PMSM power factor with a hysteresis current control, a higher value is obtained with a SV-PWM technique.
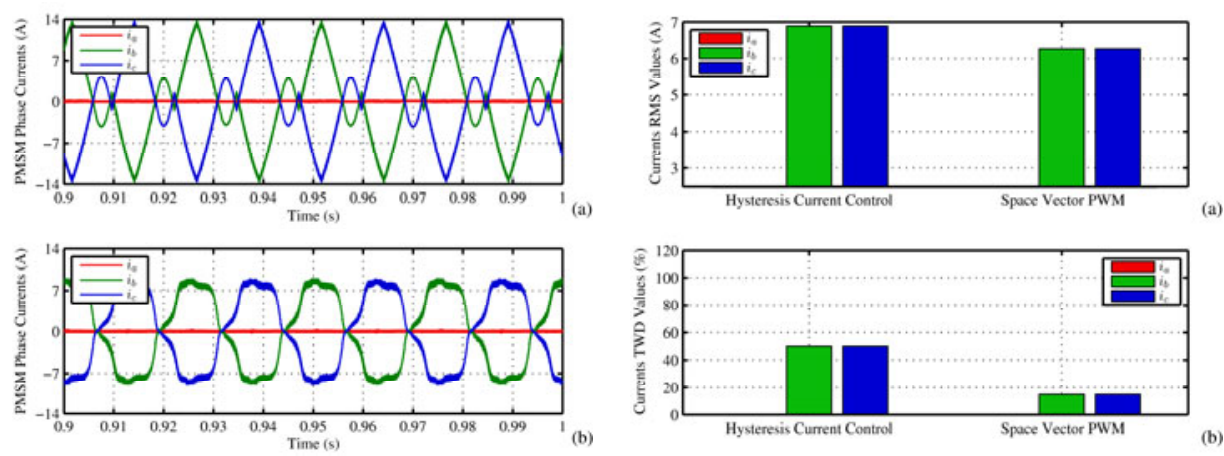

Fig. 10. Time-domain waveforms of the PMSM phase currents for a single-phase open-circuit fault in phase $a$ : (a) hysteresis current control; (b) SV-PWM

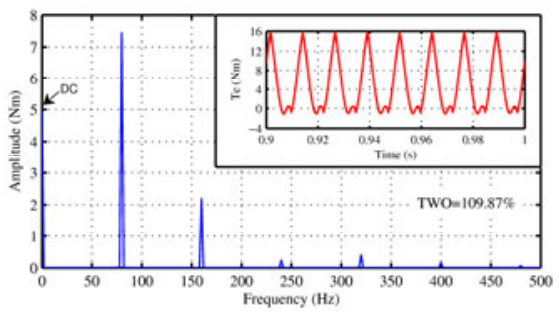

(a)
Fig. 11. PMSM phase currents rms (a) and TWD values (b) for a single-phase opencircuit fault in phase $a$

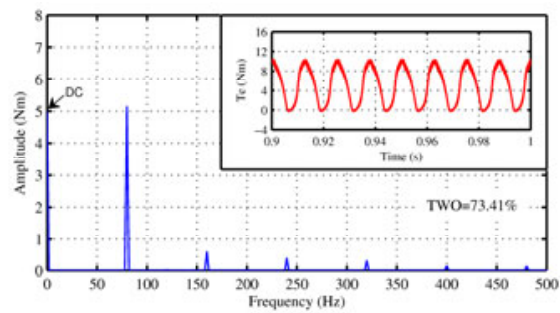

(b)

Fig. 12. Spectrograms of the PMSM electromagnetic torque and its corresponding time-domain waveforms for a single-phase open-circuit fault in phase $a$ : (a) hysteresis current control; (b) SV-PWM 
Fig. 13(b) presents the PMSM efficiency results for the two considered strategies. Due to the larger motor phase currents rms values, the efficiency values are severely affected by this fault type, when comparing to the normal operating conditions. Nevertheless, with a SV-PWM technique it is possible to obtain a higher efficiency value than with a hysteresis current control.

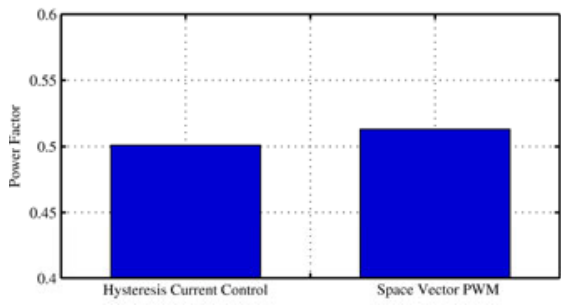

(a)

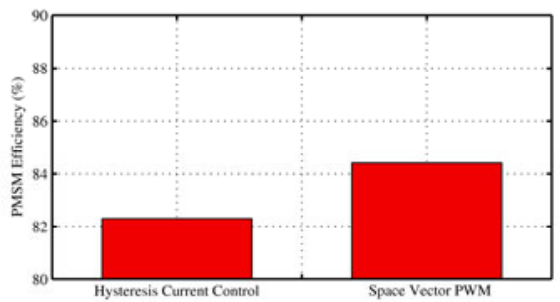

(b)

Fig. 13. PMSM power factor and efficiency results for a single-phase open-circuit fault in phase $a$ : (a) power factor values; (b) efficiency values

\section{Conclusions}

The results presented in this paper allow to conclude that with a SV-PWM technique applied to a PMSM drive, it is possible to achieve a better performance than with a hysteresis current control. Under both normal and faulty operating conditions, by using the SV-PWM technique it is possible to obtain lower rms and distortion values in the motor phase currents, a less pulsating electromagnetic torque and higher power factor and efficiency values, as compared to the use of the hysteresis current control.

Acknowledgments. The authors gratefully acknowledge the financial support of the Portuguese Foundation for Science and Technology (FCT) under Project No. SFRH/BD/40286/2007 and Project No. PTDC/EEA-ELC/105282/2008.

\section{References}

1. Bianchi, N., Bolognani, S., Zigliotto, M.: Analysis of PM synchronous motor drive failures during flux weakening operation. In: 27th Annual IEEE Power Electronics Specialists Conference, Baveno, Italy, June 23-27, vol. 2, pp. 1542-1548 (1996)

2. Welchko, B.A., Jahns, T.M., Hiti, S.: IPM synchronous machine drive response to a singlephase open circuit fault. IEEE Transactions on Power Electronics 17(5), 764-771 (2002)

3. Welchko, B.A., Jahns, T.M., Soong, W.L., Nagashima, J.M.: IPM synchronous machine drive response to symmetrical and asymmetrical short circuit faults. IEEE Transactions on Energy Conversion 18(2), 291-298 (2003)

4. Sun, T., Lee, S.H., Hong, J.P.: Faults analysis and simulation for interior permanent magnet synchronous motor using Simulink@MATLAB. In: International Conference on Electrical Machines and Systems, Seul, South Korea, October 8-11, pp. 900-905 (2007) 
5. Estima, J.O., Cardoso, A.J.M.: Performance evaluation of permanent magnet synchronous motor drives under inverter fault conditions. In: XVIII International Conference on Electrical Machines, Vilamoura, Portugal, CD-ROM, September 6-9, p. 6 (2008)

6. Estima, J.O., Cardoso, A.J.M.: Performance evaluation of DTC-SVM permanent magnet synchronous motor drives under inverter fault conditions. In: 35th Annual Conf. of IEEE Industrial Electronics Society, Porto, Portugal, November 3-5, p. 6 (2009)

7. Estima, J.O., Cardoso, A.J.M.: Impact of Inverter Faults in the Overall Performance of Permanent Magnet Synchronous Motor Drives. In: IEEE International Electric Machines and Drives Conference, Miami, USA, pp. 1319-1325 (May 2009) 